\title{
Safety and Efficacy of a Proprietary Undenatured Beta-Glucan on Different Human Populations
}

\author{
Bjørn Kristiansen, Ronald J. Amen \\ GlycaNova A.S. Fredrikstad, Norway \\ Email: ronald.amen@techenterprises.org
}

How to cite this paper: Kristiansen, B. and Amen, R.J. (2022) Safety and Efficacy of a Proprietary Undenatured Beta-Glucan on Different Human Populations. Advances in Biological Chemistry, 12, 16-28. https://doi.org/10.4236/abc.2022.121002

Received: December 22, 2021

Accepted: February 18, 2022

Published: February 21, 2022

Copyright ( 2022 by author(s) and Scientific Research Publishing Inc. This work is licensed under the Creative Commons Attribution International License (CC BY 4.0).

http://creativecommons.org/licenses/by/4.0/

\section{(c) (i) Open Access}

\begin{abstract}
After proving safety in animal and human models, a series of clinical trials were conducted to examine the administration of $1 \mathrm{mg} / \mathrm{mL}$ bid of an undenatured beta-glucan on the immune system; and on self-perceived effects on subjects' quality of life (QoL) using a Visual Analogue Scale (VAS). In one study, a subject population that was self-perceived to be fatigued was administered an undetaured beta-glucan, to determine if this supplementation affected their quality-of-life as a result of an increased immune system response. 44 subjects were administered $1 \mathrm{mg} / \mathrm{mL}$ bid of the undenatured beta-glucan (Lentinex ${ }^{\circledR}$ ) for four weeks. Prior to the beginning of the administration, and following the four-week administration period, the subjects were asked to fill out a quality-of-life VAS questionnaire. The changes in the two questionnaires revealed differences that occurred as a result of the beta-glucan administration. More than $75 \%$ of the subjects scored "better" (more than 1 $\mathrm{cm}$ on the VAS) with regard to feeling in a good mood, and feeling rested. More than $60 \%$ increased their energy and reduced their tiredness and exhaustion, and $70 \%$ felt less stressed. In a second study, subjects aged 40 years and older, believed to be in good general health, seeking therapy for tiredness/exhaustion/fatigue or similar conditions (neurasthenia) which were administered $1 \mathrm{mg} / \mathrm{mL}$ bid Lentinex ${ }^{\circledR}$. The overall results indicated that the subjects felt significantly better (mean VAS $=5.91$ ) after the last week of the study compared to how they felt initially (VAS $=4.73)(\mathrm{p}<0.0001)$. A statistically significant $(\mathrm{p}<0.0001)$ change in distribution favoring a better situation after 4 weeks intake of supplement, with a remarkable fall in number of subjects scoring below normal (from $61.4 \%$ to $18.2 \%$ ) accompanied by a significant shift in subjects feeling above normal, from $9.2 \%$ to $50.0 \%$. These clinical studies, and others, showed that Lentinex ${ }^{\circledR}$ administration improved the perceived quality-of-life of subjects whose immune system was probably
\end{abstract}


not functioning at optimal levels.

\section{Keywords}

Undenatured Beta-Glucan, Quality-of Life, Visual Analogue Scale (VAS), Lentinex $^{\circledR}$, Fatigue Population, B-Cells

\section{Introduction}

Lentinus edodes (Shiitake) is a medicinal mushroom with a long tradition of use in Asia. The major active substance in $L$. edodes is lentinan, a fraction of beta-glucan (1-6,1-3) that is typically isolated from the mushroom by solvent extraction. These beta-glucans from various sources, including mushrooms and yeast have been reported to have some positive effects on the immune system in animals and humans. However, the solvent extraction of lentinan destroys the tertiary structure of the lentinan.

Research conducted by different research institutions sought to determine if beta-glucan maintained in its tertiary structure would be more efficacious in cytokine stimulation than the denatured lentinan. Lentinan is a single fraction of beta-glucan, with a molecular weight of around 500,000 da. Beta-glucan is found in nature as $\beta-1,3$ beta-glucan with $\beta-1,6$ branching and a molecular weight typically of $\geq 500,000 \mathrm{Da}$. When the fruiting body of the shiitake mushroom is treated by a proprietary fermentation process [1] [2], it is shown that beta-glucan can be isolated in its undenatured tertiary structure. Research in the United States and in Norway has supported the understanding that undenatured beta-glucan is far superior to any other denatured beta-glucan, from mushrooms or yeast, in its ability to enhance cytokines. The negative control presented in Figure 1 is denatured lentinan.

Additionally, the immune stimulation by undenatured Lentinex ${ }^{\circledR}$, as observed in in vitro and ex vivo studies (Kristiansen), is dose dependent and affected by the molecular weight fractions, with significant stimulation observed with molecular weights of $\geq 500,000 \mathrm{Da}$. This is not seen with the denatured lentinan (Figure 2).

People whose immune systems are not operating at optimal levels are often fatigued and generally have a lower quality of life. Our research showed that supplementation with the undenatured beta-glucan complex (Lentinex ${ }^{\circledR}$ ) increases B-Cells in vivo, and in general up-regulated the cytokine complex.

\section{Human Safety Study 1}

No clinical controlled studies had previously investigated the effect of orally administered lentinan on the immune response in healthy, elderly Caucasian subjects. As a result of the animal safety studies in which no toxicity was observed with escalating doses of Lentinex ${ }^{\circledR}$, a human study was planned. The effect and 


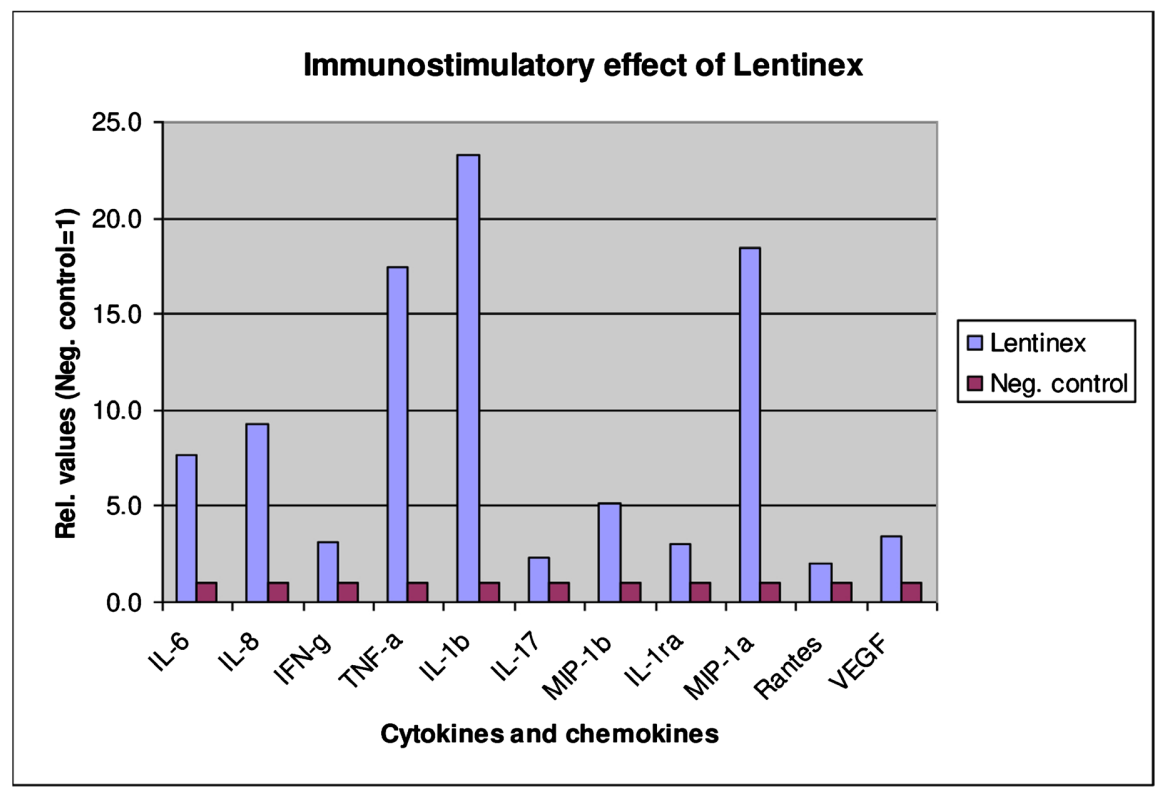

Figure 1. Comparison of Cytokine Stimulation of Undenatured Bets-Glucan (Lentinex) Compared to Denatured Beta-Glucan.

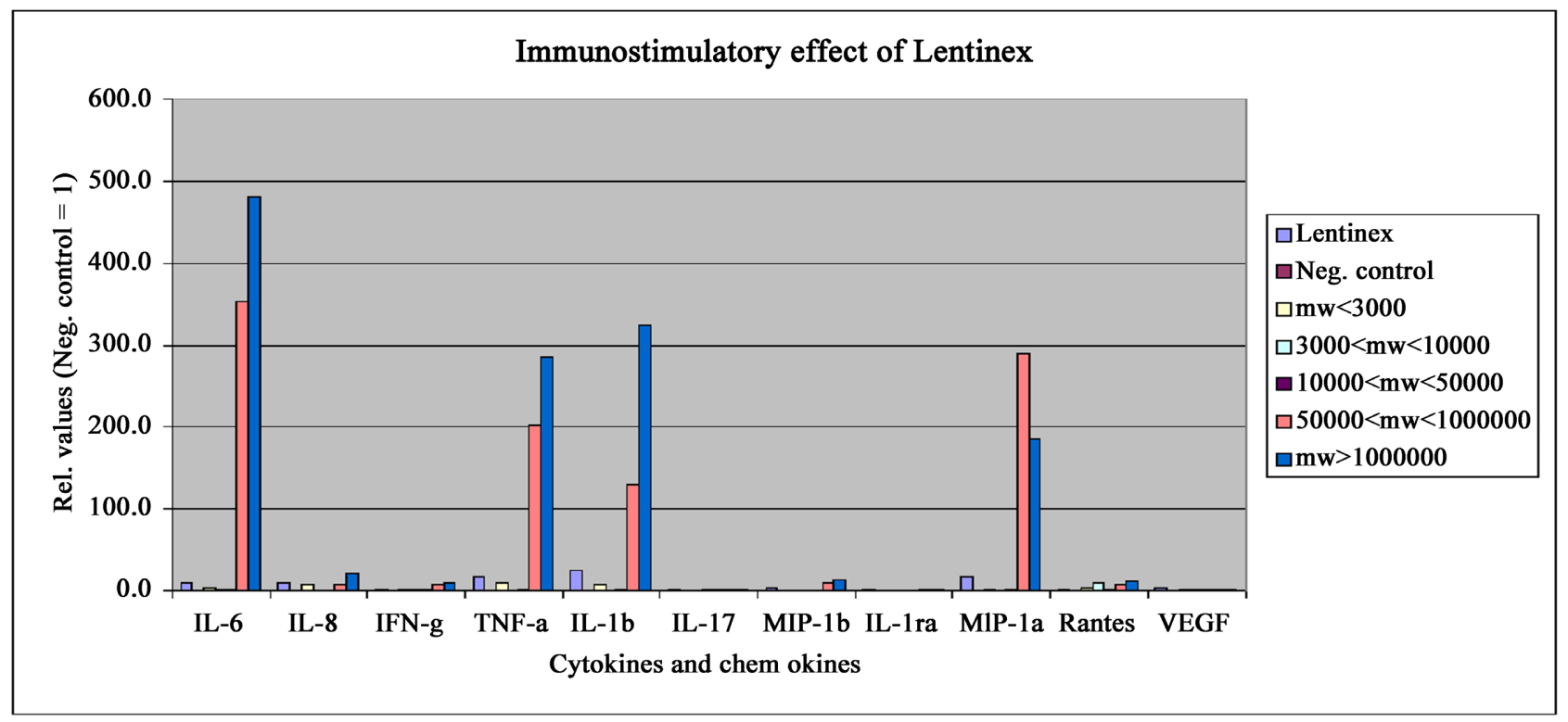

Figure 2. Cytokine Stimulation at Different Molecular Weights of Undenatured Beta-Glucan.

the safety of an undenatured beta-glucan (Lentinex ${ }^{\circledR}$ ) from L. edodes mycelium in healthy, elderly subjects in a double blind, crossover, placebo-controlled trial was conducted by Gaullier J.M. et al. [3] Forty-two subjects were randomly allocated to two groups given orally either $2.5 \mathrm{mg} /$ day Lentinex ${ }^{\circledR}$ or placebo for 6 weeks; then after a washout period of 4 weeks, the alternate supplementation was given for 6 weeks. Since these subjects were reported to be healthy, there wasn't an expectation for significant immune responses. However, the changes in the number of B-cells were significantly different between the groups $(\mathrm{p}=$ 0.0220 ) with the Lentinex ${ }^{\circledR}$-treated subjects generating a greater number of 
B-cells than did the placebo, suggesting that the immune system of these otherwise healthy subjects was not optimal. The number of NK cells increased significantly in both groups, but there was no significant difference between the groups. Other factors of the immune response (immunoglobulins, complement proteins, cytokines) were not altered. The safety blood variables (differential cell count, liver function, kidney function, and other blood chemistry) were not influenced by Lentinex ${ }^{\circledR}$, and the number, nature, and severity of adverse events were similar to placebo. The authors concluded that in this first application of Lentine ${ }^{\circledR}$ given orally to elderly subjects, the lentinan was safe and induced an increase in the number of circulating B-cells.

In a cohort of these adults that were "probably becoming ill" during the study, B-Cells of subjects given Lentinex were observed to become significantly increased. This indicates that Lentinex can enhance an antigen-challenged (i.e. "infection") immune system. This observation is consistent with the results seen in the rat study desribed above (Figure 3).

Additionally, in a second cohort of these adults that started the study with low levels of $\mathrm{B}$-Cells ( $\beta$-Lymphocytes), it was demonstrated that when given Lentinex, the B-Cells were significantly increased even when there did not appear to be an "antigen challenge" (e.g. occurrence of infection) (Figure 4). This indicates that Immuna ${ }^{\text {tw }}$ can enhance an immune system that is not functioning efficiently even if the subject is "healthy" [3].

As a result of the animal studies and the Gaullier et al. study [3], in which no toxicity was observed, a double-blind, cross-over study in healthy elderly subjects was conducted. The data that was generated in the control group showed a drop in B-Cells during the administration period. However, Lentinex $\square$ supplementation prevented the fall in the number of B-cells that was observed (p-0.038). No changes in cytokines were observed and the Lentinex $\square$ group did not differ from the placebo group.

When a subgroup with pre-treatment values below the group median at entry

\section{B lymphocytes as \% oflymphocytes and Monocytes}

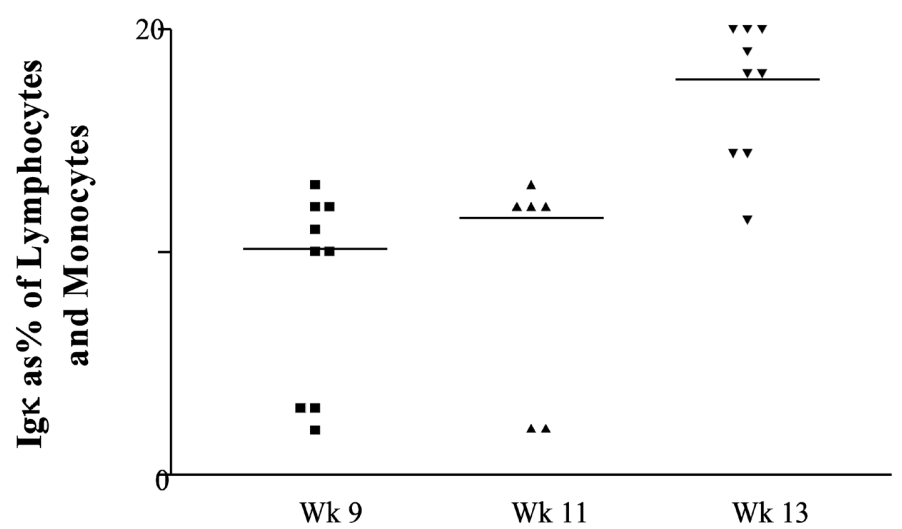

Figure 3. The Effect on B-Cells $(p<0.0001)$ When the dose of Lentinex increased from $7.8 \mathrm{mg} / \mathrm{kg}$ to $9.2 \mathrm{mg} / \mathrm{kg}$ in rats. 


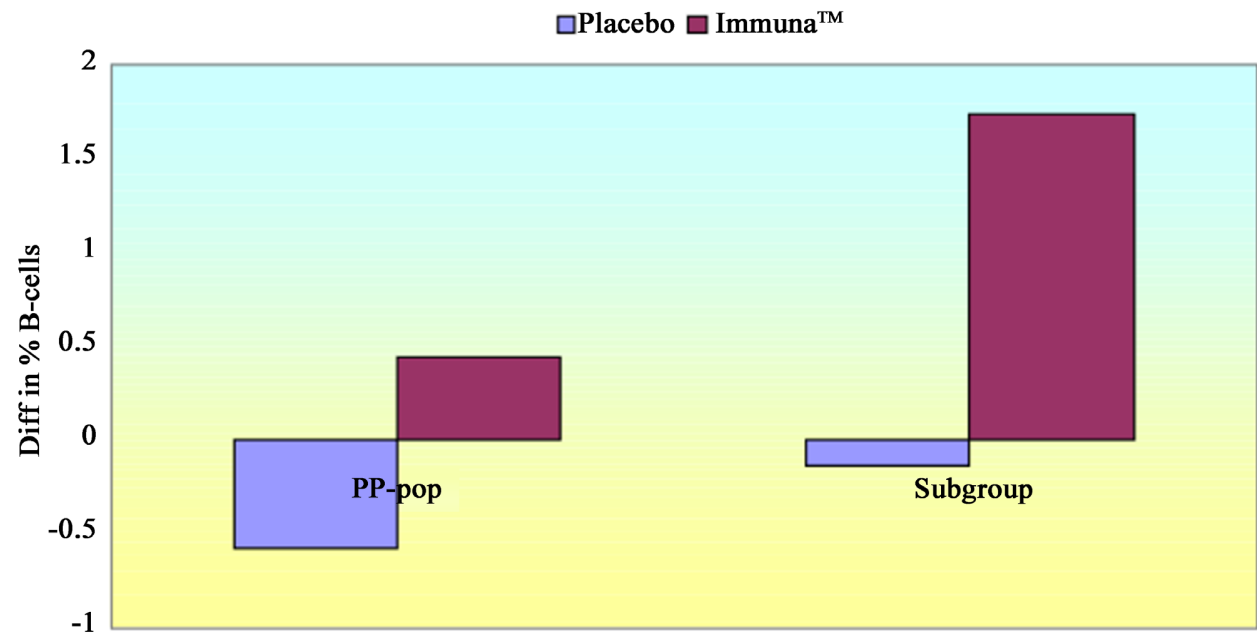

Difference in effect in healthy subjects compared to subjects with a lowered B-Cell ( $\beta$-lymphocyte) count.lmmuna ${ }^{\mathrm{TM}}$ normalized the number of $\mathrm{B}-\mathrm{Cells}$ to enhance immune defences.

GlycaNova LLC Confidential

Figure 4. When given Lentinex, the B-Cells were significantly increased even when there did not appear to be an "antigen challenge".

was analyzed, a significant response in B-cells was observed with Lentinex ${ }^{\circledR}$ administration. After 6 weeks of treatment. No such increase in B-cells were observed in the control group. The differences between the B-cells in the Lentinex ${ }^{\circledR}$ group compared to those number of B-cells in the control (placebo) group was statistically significant, $\mathrm{p}=0.017$.

Apart from showing this one critical immune marker responding to Lentinex ${ }^{\circledR}$ supplementation, the results from the study indicated that beta-glucans are most effective when the immune system is not optimal. Therefore, the intake of supplements like Lentinex ${ }^{\circledR}$ will probably work like a prophylactic, keeping the immune system alerts (i.e. "immune surveillance"). This would be in accordance with the observations that lentinan reduces infections when pre-fed to mice before they are exposed to an antigenic insult (murine Listeria monocytogenes) [4], but do not express antibacterial effects in vitro.

From our results, and others, we concluded that the referenced studies, strongly suggest that when Lentinex ${ }^{\circledR}$ is administered to animals and humans with less than optimal immune systems, the Lentinex ${ }^{\circledR}$ will enhance the immune system by "normalizing" (i.e. increasing) lowered level of B-cells. Thus, when antigens are present (as in disease), an increased number of antibodies are able to be produced (adjuvant effect).

It is important to note that while many publications have been written regarding mechanisms, conditions, diseases, and effects ([5] [6] [7] [8]; of lentinan on certain organ systems, not one has been written that describes the affect of beta-glucans on the subjects' perceived changes in quality-of-life. These studies address this omission.

Finally, our research confirmed that commercial lentinans are primarily denatured, and as such have little immune stimulating ability compared to unde- 
natured lentinan

\section{Statistical Methods}

Paired differences were tested for normality (Anderson-Darling test). As the observed differences, in general, were normally distributed, parametric tests as paired T-tests were used. Chi-square was used where appropriate.

\section{Quality of Life VAS Questionnaire}

As reported in prior studies [8] a Quality-of-Life questionnaire (QoL) containing eight items was used for assessment of the change in the subject's perception of their life quality during the course of the study. Each item was scored by use of a $100 \mathrm{~mm}$ visual analogue scale (VAS). The modified QoL questionnaire was analyzed using the individual differences in score (VAS in $\mathrm{mm}$ ) between baseline and end of study for each item. The following items were scored:

Q1: How did you feel last week?

Q2: Have you felt depressed last week?

Q3: I have been in good mood and rested when i woke up.

Q4: I have felt myself active and with energy the last week.

Q5: I have been happy and carefree the last week.

Q6: I have been tired, worn and exhausted the last week.

Q7: Have you felt relaxed and in good spirit or stressed and tense?

Q8: Have you felt listless and without initiative the last week?

The QoL questionnaire was analyzed using the individual changes in score (VAS in $\mathrm{mm}$ ) between baseline and end of study. Questions 3, 4, 5, and 7 were inverted through the formula: (Value to be used in calculations) $=100-$ (Value measured length in mm on VAS from left end to mark). An individual difference of more than $10 \mathrm{~mm}$ for a single item was considered a clinically meaningful change.

Subjects who volunteered to participate in the survey, were asked to visit the center and were asked to fill in an initial questionnaire. This questionnaire addressed their Quality-of-Life prior to entering the study. The therapist explained how to fill-out the VAS/questionnaire, which addressed and rated the subjects' feelings on a zero to 9.0 scale, with zero being "terrible" and 9.0 being "excellent."

\section{Effect of Lentinex on Fatigued Population}

The aim of this opinion survey was to evaluate perceived changes after four weeks consumption of a beta-glucan supplement (Lentinex ${ }^{\circledR}$ ), in a total of 44 subjects, (32 females and 12 men).

The results indicate that the subject distribution, and the group score for each question, changed in a favorable direction for all questions and all reached statistical significance. The typical "fatigue" questions had the highest positive results. More than $75 \%$ of the subjects scored "better" (more than $1 \mathrm{~cm}$ on the VAS) with 
regard to feeling in a good mood, and feeling rested. More than $60 \%$ increased their energy and reduced their tiredness and exhaustion, and 70\% felt less stressed.

The author concluded that the results from the primary endpoints show that there is a statistically significant and probable relevant change towards a more favorable situation for all questions. Being rested in the morning and feeling less stressed was experienced by about $75 \%$ of individuals. Further, increased energy and less tiredness and exhaustion were experienced by the majority of subjects after four weeks consuming the beta-glucan supplement for four weeks. The results strongly indicate that intake of Lentinex ${ }^{\circledR}$ for four weeks, had favorable effects on a "fatigued" population [9].

\section{Human Quality of Life Study}

In this study, some quality of life questions were used to evaluate whether subjective changes after eight weeks consumption of a beta-glucan supplement Lentinex ${ }^{\circledR}$ in healthy subjects, could be of importance with regard to subject safety. In an earlier study [3] it was found that subjects taking Lentinex ${ }^{\circledR}$, suffered less from sleepiness and tiredness/exhaustion when using Lentinex ${ }^{\circledR}$. Additionally, patients with some fatigue syndromes like "low natural killer cell syndrome (LNKS)" have had positive outcome after taking a beta-glucan, [10] and beta-glucans have been favorably used in neurasthenia.

With this background, the present study also presented an opportunity to investigate if healthy subjects (both genders, age $>45$ years old) were to be eligible for study (in general would perceive a change in "quality of life"(QoL), using the same questionnaire as had been used in the previously conducted study in a "fatigue" population. As the aim of the study did not primarily include QoL as an efficacy variable, the present study did not use entry criteria with regard to pre-treatment QoL score.

The present study was a randomized, placebo controlled, double blind, parallel-group study investigating four different dose levels of the investigational product $\left(\right.$ Lentinex ${ }^{\circledR}$ ). Healthy subjects were recruited to one study centre, and randomized to receive placebo or Lentinex ${ }^{\circledR}$. Each subject randomised to treatment with the investigational product received four dose levels of Lentinex ${ }^{\circledR}$ during the study period. Each dose of the investigational product was taken daily for two weeks, and the treatment period was eight weeks in total. The subjects visited the study centre six times during the study period; for screening (week -2 ), at treatment start (week 0), and at the end of each dose level phase (week 2, 4,6 and 8 ).

The QoL questionnaire was additionally analyzed by calculating the number of subjects scoring "worse" $(>-10 \mathrm{~mm})$, unchanged $( \pm 10 \mathrm{~mm})$ or "better" $(<+10$ $\mathrm{mm}$ ) for each item at the end of the study. The distribution of subjects with a score equal to $50 \pm 10 \mathrm{~mm}$ ("normal"), lower than $40 \mathrm{~mm}$ (lower than "normal"), or higher than $60 \mathrm{~mm}$ (higher than "normal") were compared before and after treatment. 
The mean score of all eight items was additionally calculated at baseline and after the end of the treatment phase ( 8 weeks). The change in score from baseline showed that the subjects on Lentinex ${ }^{\circledR}$ experienced an improvement in life quality (estimate $=+2.1$ ), whereas the subjects in the placebo group experienced a worsening of life quality (estimate $=-6.6$ ) during the study period. The difference between the treatment groups was statistically significant $(\mathrm{p}=0.059)$.

As observed with regard to tiredness and exhaustion, 25\% of the subjects stated improvement (less tired and exhausted) in the active group, compared to none in the placebo group, in which 40 percent said they were more exhausted. Forty percent increased their initiative in the active group, compared to 10 percent in the placebo group.

In Figure 5, the improvement in all QoL parameters in the group on Lentinex ${ }^{\circledR}$ was noticably better than the group on placebo. Statisticall significant changes are given by p-values, and both question 6 (I have been tired, worn and exhausted the last week) and question 8 (have you felt listless and without initiative the last week) were statistically different from placebo, $\mathrm{p}<0.045$ and $\mathrm{p}<$ 0.031, respectively. Additionally, although subjects on both Lentinex and placebo both recorded improvements in question 7 (Have you felt relaxed and in good spirit or stressed and tense?), the difference was not significant, but the improvement of the group on Lentinex ${ }^{\circledR}$ was tending toward a significant improvement of the Lentinex ${ }^{\circledR}$ group compared to placebo.

Despite high entry scores, mean 65.0, range 50.9 to 71.1 , at baseline, changes in all items were in favour of Lentinex ${ }^{\circledR}$. The change in score, however, from baseline showed that the subjects of the Lentinex ${ }^{\circledR}$ experienced a small, but distinct improvement in life quality (estimate $=+2.1$ ), whereas the subjects in the

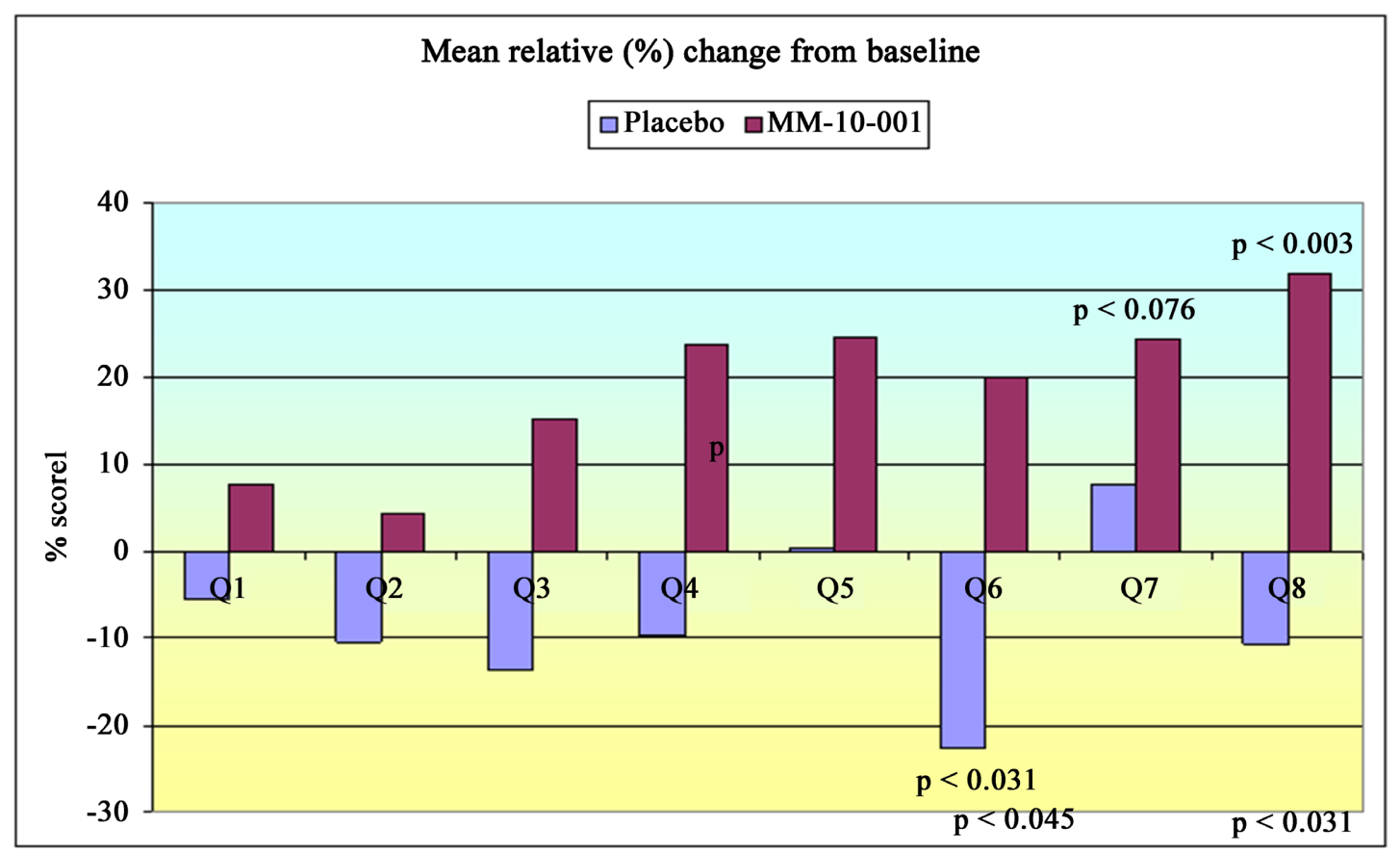

Figure 5. Relative changes in quality-of-life indicators over the course of the study. 
placebo group experienced a worsening of life quality (estimate $=-6.6$ ) during the study period. The difference between the treatment groups was statistically significant $(\mathrm{p}=0.059)$.

It should be noted that with regard to tiredness and exhaustion, $25 \%$ of the subjects stated improvement in the active group, compared to none in the placebo group, in which $40 \%$ of the subjects reported more exhaustion. Forty percent of the subjects increased their initiative in the active group, compared to 10 percent of the subjects in the placebo group [11].

\section{Effect of Lentinex on Quality-of-Life Home Survey Study}

This study was carried out to investigate the effect of Lentinex supplementation on the well-being of adults in a free-living environment. The effects of Lentinex in healthy adult subjects were studied in a randomized, placebo-controlled, double-blind trial. Sixty-three nursery school teachers were randomly allocated to two groups, and took either Lentinex ${ }^{\circledR}$ ( $1-2 \mathrm{~mL} /$ day; $1-2 \mathrm{mg}$ beta glucan) or placebo, for four weeks orally.

56 participants completed the 8-question survey-study, producing 444 changes from initial to final questionnaire scores. 30 of the participants initially rated themselves under six (less than "normal") in half of the eight well-being questions.

Of the 30 subjects who initially rated themselves under six in half of the eight well-being questions, those taking Lentinex reported an average improvement of 1.0 per question, relative to the placebo group $(p=0.0007)$. Overall, their improvement was 0.9 per question across all eight questions relative to placebo ( $\mathrm{P}$ $=0.0004)$ (Figure 6).

45 of the initial scores in the Lentinex treatment group were below three (out of 10) and their average improvement was a highly significant $2.8(\mathrm{p}<0.0000)$. 87 initial Lentinex-group scores were below four, which improved by 2.1 ( $\mathrm{p}<$ $0.0000)$ on average. For 183 initial Lentinex-group scores below six the average improvement was $1.3(\mathrm{p}<0.0000)$.

The results from this study showed that daily supplementation with Lentinex ${ }^{\circledR},(1 \mathrm{mg} / \mathrm{mL})$, generated a statistically significant $(\mathrm{p}=0.004)$ increase in well-being as compared to placebo. Importantly, the greater the need for improved well-being, indicated by participants reporting lower starting scores on their initial questionnaire, the greater the improvement with Lentinex relative to placebo; "the more help needed, the more Lentinex helped".

\section{Discussion}

These studies clearly demonstrate the positive effects of Lentinex ${ }^{\circledR}$ on B-cells, and the subsequent positive effects of B-Cells on subject-perceived quality-of-life.

$\underline{B-C e l l s}$

The safety and efficacy of Lentinex ${ }^{\circledR}$ has been established. In early in vitro, ex vivo, and in vivo safety and efficacy studies in mice and rats, when lentian was administered, an increase in B-cells was observed. In a study we sponsored in the 


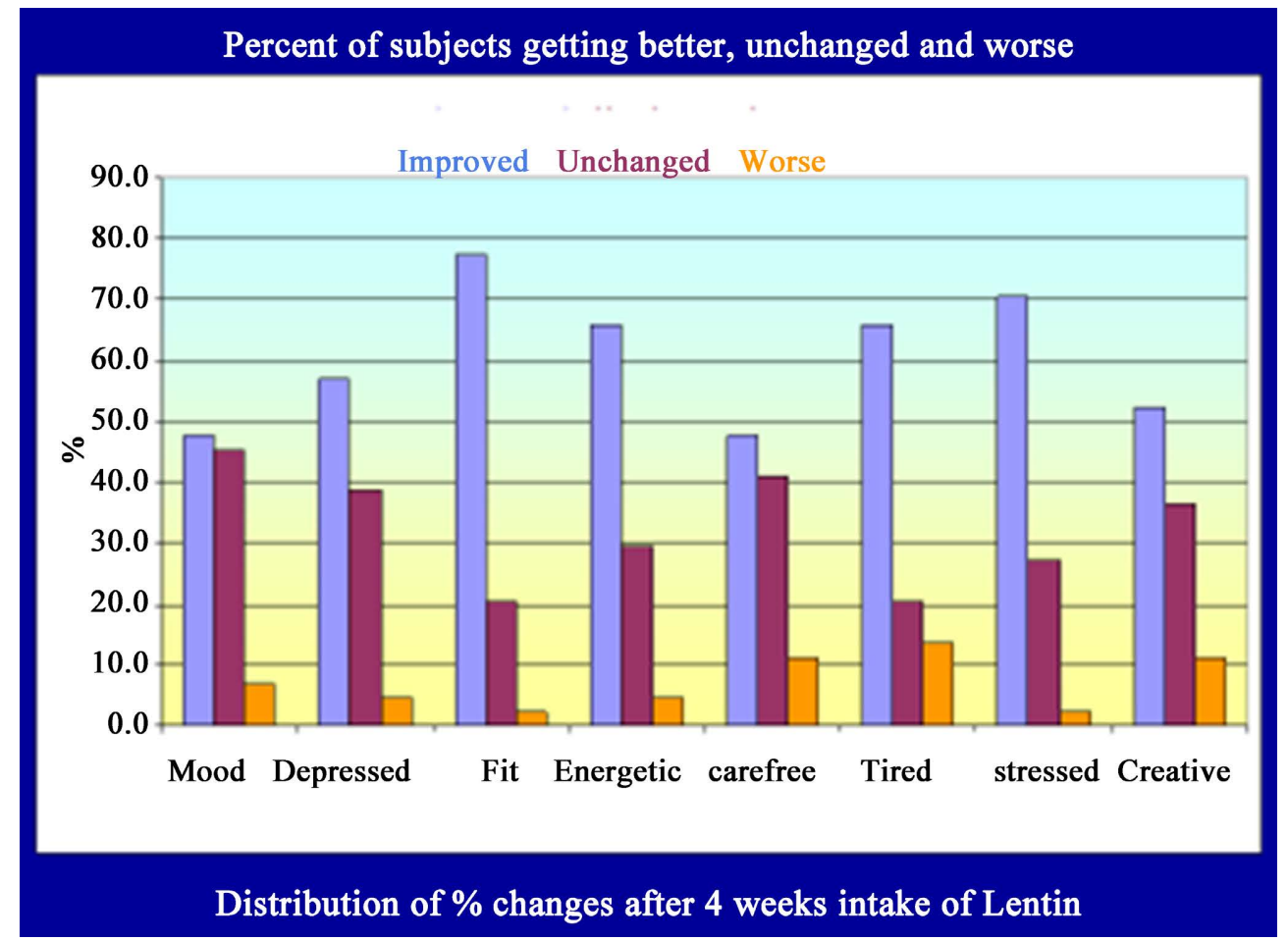

Figure 6. 30 subjects who initially rated themselves under six in half of the eight well-being questions, reported an average improvement of 1.0 per question after taking Lentinex, relative to the placebo group ( $\mathrm{p}=0.0007$ ). Overall, their improvement was 0.9 per question across all eight questions relative to placebo $(\mathrm{p}=0.0004)$.

United States, an almost doubling of B-cells, from $16 \%$ in controls to $25 \%$ after oral intake of Lentinex ${ }^{\circledR}$ [4], was observed in mice. The effect of increasing doses of Lentinex ${ }^{\circledR}$ on B-cells could also be observed in a rat safety study we sponsored [4]. A considerable increase in B-cells $(p<0.0001)$ was observed after increasing the dose from $7.8 \mathrm{mg} / \mathrm{kg}$ to $9.2 \mathrm{mg} / \mathrm{kg}$ in rats.

B-Cells ( $\beta$-lymphocytes) produce anti-bodies, and as such, are paramount in the body's ability to fight infection and other antigen invasions. All studies showed that most or all individuals, whether they were purported to be healthy or not, or whether then felt they had an acceptable quality-of-life, had B-cells that were not optimized to meet an antigen insult. The most important thing that came out of these studies is that most or all subjects studied needed immune enhancement/optimization so that 1) they would be more prepared to fight any antigen, and 2) they could reduce some of their less-than-desired quality-of-life factors; specifically, those related to energy.

Gaulier et al. [3] reported on "healthy," elderly, Caucasian subjects, a population in which there wasn't an expectation for significant immune responses. After Lentine ${ }^{\circledR}$ administration the subjects experienced changes in the number of their B-cells. These amounts were significantly different between the groups ( $\mathrm{p}=$ 0.0220 ) with the Lentinex ${ }^{\circledR}$-treated subjects generating a greater number of B-cells than did the placebo, suggesting that the immune system of these otherwise healthy subjects, prior to treatment, was not optimal. 
Additionally, in a second cohort of these adults that started the study with low levels of B-Cells, it was demonstrated that when given Immuna ${ }^{\mathrm{m} 11}$, the B-Cells were significantly increased even when there did not appear to be an "antigen challenge" (i.e. occurrence of infection) This indicates that Immuna ${ }^{\text {tax }}$ can enhance an immune system that is not functioning efficiently even if the subject is "healthy."

When a subgroup of "healthy" subjects with pre-treatment values below the group median at entry was analyzed, a significant response in B-cells was observed following Lentinex ${ }^{\circledR}$ administration. No such increase in B-cells were observed in the control group. The differences between the B-cells in the Lentinex ${ }^{\circledR}$ group compared to those number of B-cells in the control (placebo) group was statistically significant, $\mathrm{p}=0.017$.

Quality-of-Life

Three studies examined the effects of Lentinex ${ }^{\circledR}$ on quality of life. It is known that a less-than-optimal immune system is often the cause of lack of energy and overall fatigue. Having a weak immune system results in the body using its energy reserves to constantly combating infections and other antigens. Having a strong immune system typically results in an increase in energy and an overall improvement in quality-of life.

Administration of Lentinex ${ }^{\circledR}$ increased the self-perception of the subjects' well-being when taken over time. Being rested in the morning and feeling less stressed was experienced by about $75 \%$ of individuals. Further, increased energy and less tiredness and exhaustion were experienced by the majority of subjects after four weeks consuming the beta-glucan supplement for four weeks.

In one study the change in score from baseline showed that the subjects on Lentinex ${ }^{\circledR}$ experienced an improvement in life quality (estimate $=+2.1$ ), whereas the subjects in the placebo group experienced a worsening of life quality (estimate $=-6.6$ ) during the study period. The difference between the treatment groups was statistically significant ( $\mathrm{p}=0.059)$.

In a second study, subjects age 40 years and older, believed to be in good general health,seeking therapy for tiredness/exhaustion/fatigue or similar conditions (neurasthenia) were administered Lentinex ${ }^{\circledR}$. The overall results indicated that the subjects felt significantly better (mean VAS $=5.91$ ) after the last week of the study compared to how they felt initially (VAS $=4.73)(\mathrm{p}<0.0001)$. A statistically significant $(\mathrm{p}<0.0001)$ change in distribution favoring a better situation after 4 weeks intake of supplement, with a remarkable fall in number of subjects scoring below normal (from $61.4 \%$ to $18.2 \%$ ) accompanied by a significant shift in subjects feeling above normal, from $9.2 \%$ to $50.0 \%$.

The subjects had statistically significant improvements in reduction of depression, fatigue, and stress. They had statistically significant improvements in mood, energy, happiness, and initiative. The typical "fatigue" questions had the highest positive results. More than $75 \%$ of the subjects scored "better" (more than $1 \mathrm{~cm}$ on the VAS) with regard to feeling in a good mood and being rested. More than $60 \%$ increased their energy and reduced their tiredness and exhaus${ }^{1}$ Immuna $^{\mathrm{Tm}}$ is a tradename for Lentinex ${ }^{\circledR}$. 
tion, and $70 \%$ felt less stressed.

30 subjects in a free-living environment, who initially rated themselves under six (normal or average) in half of the eight well-being questions, those taking Lentinex reported an average improvement of 1.0 per question, relative to the placebo group $(\mathrm{p}=0.0007)$. Overall, their improvement was 0.9 per question across all eight questions relative to placebo $(\mathrm{p}=0.0004)$.

45 of the initial scores in the Lentinex treatment group were below three (out of 10) and their average improvement was a highly significant 2.8 ( $\mathrm{p}<0.0000)$. 87 initial Lentinex-group scores were below four, which improved by 2.1 ( $\mathrm{p}<$ $0.0000)$ on average.

The results from this study showed that daily supplementation with Lenti$\mathrm{nex}^{\circledR},(1 \mathrm{mg} / \mathrm{mL})$, generated a statistically significant $(\mathrm{p}=0.004)$ increase in well-being as compared to placebo. Importantly, the greater the need for improved well-being, indicated by participants reporting lower starting scores on their initial questionnaire, the greater the improvement with Lentinex relative to placebo; "the more help needed, the more Lentinex helped".

The results of these studies were consistent. Subjects who described themselves as healthy were shown to have less than optimal B-Cells at the beginning of the trials, but following four weeks on undenatured beta-glucan, a significant increase in B-Cells were observed as compared to subjects administerd placebo. This provided the subjects with an improved immune system to fight infection and other antigen insult. Subjects that had less than desired self-perceived quality-of life were also administered undenatured beta-glucan. After four weeks of treatment with undenatured beta-glucan, the subjects' self-perceived QoL increased significantly, especially as it related to increased energy, decreased fatigue, decreased stress, and positive changes in other quality-of-life descriptors. The increase in energy and general well-being is a sign that the immune system was sub-optimal. Once the immune system, e.g. B-Cells, was optimized by Lentinex $^{\circledR}$, fatigue and other quality-of-life indicators were improved. There appears to be a direct relationship between improved B-Cell numbers and QoL, when undenatured beta-glucan is administered.

\section{Conclusion}

Subjects that were administered daily doses of Lentinex ${ }^{\circledR}$ at $1 \mathrm{mg} / \mathrm{mL}$ bid stated that their overall quality of life improved over the study period. They indicated that this improvement was manifested by a significant increased energy/decreased fatigue, decreased stress, and decreased depression.

\section{Conflicts of Interest}

The authors declare no conflicts of interest regarding the publication of this paper.

\section{References}

[1] Kristiansen, B. (2009) Immune Modulating Compounds from Fungi US 7,514,085 
April 6, 2009.

[2] Kristiansen, B. (2010) Immune Modulating Compounds from Fungi. US 7,682,615, March 23, 2010.

[3] Gaullier, J.-M., Sleboda, J., Øfjord, E.S., et al. (2011) Supplementation with a Soluble Beta-Glucan Exported from Shiitake Medicinal Mushroom, Lentinus Edodes (Berk) Singer Mycelium: A Crossover, Placebo-Controlled Study in Healthy Elderly. International Journal of Medicinal Mushrooms, 13, 319-326. https://doi.org/10.1615/Int/MedMushr.v13.i4.10

[4] O'Reilly, K.L. (2005) Effect of Glyca Nova's Proprietary Bio-Active Beta-(1,3)(1,6)-D-Glucan on Complement, Cytokine, and Chemokine Systems Activation, and the Effect of the Tertiary Structure on the Bio-Activity of the Molecule.

[5] Gjertsen, B. (2006) Evaluation of Lentinex ${ }^{\circledast}$ Toxicity in Healthy BN Rats. Institute of Medicine, Haematology Section, University of Bergen and Department of Internal Medicine, Haematology Section, Haukeland University Hospital, Bergen, Norway.

[6] Giorgio, G., Tabouret, G. and Quintin, J. (2018) The Complexity of Fungal $\beta$-Glucan in Health and Disease: Effects on the Mononuclear Phagocyte System. Front Immunol. Frontiers in Immunology, 9, 673. https://doi.org/10.3389/fimmu.2018.00673

[7] Anna, C., Drywień, M.E., Hamulka, J. and Sadkowski, T. (2019) Nutraceutical Functions of Beta-Glucans in Human Nutrition. Roczniki Państwowego Zakładu Higieny [Annals of the National Institute of Hygiene], 7, 4.

[8] Ayaka, N., Yamada, K., Iwata, O., et al. (2018) $\beta$-Glucan in Foods and Its Physiological Functions. Journal of Nutritional Science and Vitaminology (Tokyo), 64, 8-17. https://doi.org/10.3177/jnsv.64.8

[9] Fjeldstad, B. (2008) Effect of Lentinex ${ }^{\circledast}$ in a "Fatigue" Population Visiting an Aroma Therapeutic Clinic: An Opinion Survey.

[10] El Khoury, D., Cuda, C., Luhovyy, B.L. and Anderson, G.H. (2012) Beta Glucan: Health Benefits in Obesity and Metabolic Syndrome. Journal of Nutrition and Metabolism, 2012, Article ID 851362. https://doi.org/10.1155/2012/851362

[11] Fjord, E.S. (2008) Clinical Study Short Report on QoL Dose Escalation Safety Study of Lentinex ${ }^{\circledast}$ in Healthy Subjects: A Double Blind Placebo-Controlled Study, Bergen II, Centre for Clinical Trials (CENCLIN), Gamlehaugvei 20, N-5231 Paradis, Norway. 